\title{
Formation Criteria of High Efficiency Perovskite Solar Cells in Ambient Conditions
}

\author{
Clara Aranda, ${ }^{1 \dagger}$ Cesar Cristobal, ${ }^{1 \dagger}$ Leyla Shooshtari, ${ }^{1,2}$ Cheng $\mathbf{~ i i},{ }^{3}$ Sven Huettner, ${ }^{3}$ \\ Antonio Guerrero ${ }^{{ }^{*}}$ \\ ${ }^{1}$ Institute of Advanced Materials (INAM), Universitat Jaume I, 12006 Castelló, Spain \\ 2 Institute for Nanoscience and Nanotechnology, Sharif University of Technology, \\ Tehran, 14588-89694, Iran \\ ${ }^{3}$ Organic and Hybrid Electronics, Macromolecular Chemistry I, University of Bayreuth, \\ Universitätstr. 30, 95447 Bayreuth, Germany \\ ${ }^{\dagger}$ Both authors contributed equally
}

Email: aguerrer@uji.es

23 January 2017

\begin{abstract}
The field of lead halide perovskites for solar cell applications has recently reported impressive power conversion (PCE) above $22 \%$ using complex mixed cation formulations. Very importantly, highest PCE have been obtained using totally dry environmental conditions increasing the processing costs (i.e. use of glovebox). In this work devices processed in air under different ambient conditions are prepared with PCE approaching $19 \%$ for the simplest lead halide perovskite $\left(\mathrm{MAPbI}_{3}, \mathrm{MA}=\right.$ Methyl ammonium). It is shown that the $\mathrm{PbI}_{2}$ :MAI:additive complex needs to be generated in the correct stoichiometry $(1: 1: 1)$ where additives are any highly polar molecule able to stabilize the complex (i.e. $\mathrm{H}_{2} \mathrm{O}$ or Dimethylsulphoxide (DMSO)). At high humidity conditions $\mathrm{H}_{2} \mathrm{O}$ is incorporated into the complex and only small concentrations of further additives are needed. Precursor formulations not adequately balanced for the humidity conditions lead to films with poor morphology as evidenced by SEM. These films show negative multiiodide plumbate chemical defects as observed by absorbance measurements. These chemical defects act as recombination centers reducing the photocurrent and Fill Factor in photovoltaic devices. In addition, it is shown the undesirable high conductivity of the perovskite hydrates $\left(\sigma=8 \times 10^{-1} \mathrm{Scm}^{-1}\right)$, up to seven orders of magnitude higher than the pure $\mathrm{MAPbI}_{3}$, indicating that the presence of hydrates may act as shunting pathways that can significantly reduce the open circuit potential.
\end{abstract}

Keywords: Perovskite, coordination chemistry, defects, humidity, absorption. 
Photovoltaic devices based on lead halide perovskites have emerged as strong candidates to compete with already commercially available technologies. ${ }^{1}$ Impressive certified power conversion efficiencies (PCE) of $21.6 \%$ have been obtained using complex formulations where several cations are included in the basic formula $\mathrm{ABX}_{3}$ where $\mathrm{A}$ is a monovalent cation $(\mathrm{A}=$ Cesium, Methylammonium (MA), formamidinium and rubidium), $\mathrm{B}$ is a divalent metal $(\mathrm{B}=\mathrm{Pb})$ and $\mathrm{X}$ is a halogen $(\mathrm{X}=$ Iodide and Bromide). ${ }^{2}$ Alternatively, highest reported efficiencies for more simple formulations like $\mathrm{MAPbI}_{3}$ is in the range of $18-19 \% .^{3,4}$ Very importantly, highest PCE are typically obtained for perovskite layers processed under totally dry conditions which would ultimately increase the costs associated to production. Unfortunately, there is not a clear answer in the field on whether the presence of environmental water is positive or negative. Indeed, the beneficial effect of environmental water has been independently reported by different authors but record efficiencies are obtained under dry conditions. ${ }^{5}$, ${ }^{6}$ To further add complexity to the topic very often research articles do not provide details on whether the process has been carried out in a glovebox, humidity controlled laboratories or in ambient conditions. For this reason there is a need to find a robust process in ambient conditions able to provide perovskite solar cells with high efficiencies based on the good understanding of the effect of water on crystallization and physical implications.

Crystallization of $\mathrm{MAPbI}_{3}$ is typically carried out from highly coordinating solvents required to dissolve the $\mathrm{PbI}_{2}$ precursor including Dimethylsulphoxide (DMSO), N,NDimethylformamide (DMF) or $\gamma$-Butyrolactone (GBL). ${ }^{7-11}$ The latest improvements in device efficiency are all connected with the production of perovskite films with few defects that show very high carriers diffusion lengths exceeding tens of micrometers. ${ }^{12}$ Indeed, increased crystallinity of the perovskite layer is related with low presence of grain boundaries and impurities, both factors limiting the device performance. ${ }^{13}$ Recently, the perovskite layer has been prepared highly reproducibly in a one step process by generation of the $\mathrm{PbI}_{2}$ :MAI:DMSO complex from DMF solvent. ${ }^{7}$ The use of a solvent like $\mathrm{Et}_{2} \mathrm{O}$ or toluene is required to wash out the carrier solvent during spin coating of the perovskite layer whilst not dissolving the perovskite layer. A final thermal treatment promotes the slow evaporation of the weakly bound polar additive (DMSO). ${ }^{3 \text {, }}$ ${ }^{7}$ Similarly, high quality perovskite layers can be produced in a two-steps method where a thin homogeneous layer of $\mathrm{PbI}_{2}$ is prepared via the coordination complex with either DMSO, ${ }^{14} \mathrm{H}_{2} \mathrm{O}^{15}$ and more recently with acetonitrile. ${ }^{16}$ In this case, the weakly bound additive is displaced by the subsequent addition of either MAI or FAI, followed by a thermal treatment.

Similarly to DMSO, water molecules are highly coordinating molecules known to be key players during degradation and crystallization of the perovskite layer. Several authors have described the effect of water during degradation of perovskite solar cells. ${ }^{6}$, ${ }^{17-20}$ It has been reported that water in the gas phase rapidly diffuses in perovskite films to generate hydrates via a two-step process starting with formation of $\mathrm{MAPbI}_{3} \cdot \mathrm{H}_{2} \mathrm{O}$ 
followed by $(\mathrm{MA})_{2} \mathrm{PbI}_{6} \cdot \mathrm{H}_{2} \mathrm{O}$ after prolonged exposure to moisture. ${ }^{17} \mathrm{~A}$ perfect understanding on the actual role of water during crystallization of the perovskite layer has been more elusive due to the high complexity of the system. ${ }^{21}$ For example, depending on the selected process a small amount of water arising from ambient moisture may be required to provide adequate film morphology. ${ }^{5,22}$ Similarly, Snaith et al. described film formation under different relative humidity (R.H.) conditions and showed that the presence of water leads to less continuous morphology but significantly improved photoluminescence, film formation is faster, and showed improved device performance. ${ }^{6}$ In the most extreme case liquid $\mathrm{H}_{2} \mathrm{O}$ has been added to the precursor solution to generate devices with high quality of $\mathrm{MAPbBr}_{3} .{ }^{23}$ Unfortunately, these results are in apparent contradiction with results obtained for top efficiency devices which are typically produced under totally dry environment. ${ }^{2,24}$

Here we report the separation of effects related to water present in the ambient from that of solvent/additives (i.e. DMSO). Crystallization of $\mathrm{MAPbI}_{3}$ is systematically studied as a function of the DMSO:Pb ratio and R.H. in the ambient using a one-step perovskite deposition method. Both, water and DMSO will compete to coordinate to the lead atom for generation of $\mathrm{PbI}_{2}$ :MAI:Additive complex. We correlate the presence of DMSO and $\mathrm{H}_{2} \mathrm{O}$ during processing of the films with the final morphology of the films and generation of chemical defects. Overall, we provide a clear picture on the role of water and additives during crystallization of the perovskite layer and how the coordination chemistry will dictate the nature of chemical defects that limit the device performance.

\section{Experimental}

Materials and precursor solutions

All materials were used as received:FTO glasses $(25 \times 25 \mathrm{~mm}$, Pilkington TEC15, $\sim 15 \Omega / \mathrm{sq}$ resistance), $\mathrm{TiO}_{2}$ paste (Dyesol 30NRD, $300 \mathrm{~nm}$ average particle size), $\mathrm{CH}_{3} \mathrm{NH}_{3} \mathrm{I}$ (DYESOL), $\mathrm{PbI}_{2} \quad$ (TCI, $99.99 \%$ ), titanium diisopropoxidebis (acetylacetonate) (75\% in isopropanol, Sigma-Aldrich), spiro-OMeTAD (Merck). The perovskite precursor solution was prepared by reacting DMF solutions (50 wt \%) containing MAI and $\mathrm{PbI}_{2}(1: 1 \mathrm{~mol} \%)$ and MAI, PbI2 and DMSO (1:1:1 mol \%) and for the different humidities, the molar ratio of DMSO was changed from $0 ; 0.5 ; 0.75$; $1 ; 1.25 ; 1.5$, as is shown in figures above. The spiro-OMeTAD solution was prepared by dissolving in $1 \mathrm{~mL}$ of chlorobenzene $72.3 \mathrm{mg}$ of $\left(2,2^{\prime}, 7,7^{\prime}\right.$-tetrakis(N,N'-di-pmethoxyphenylamine)-9,9'-spirobifluorene), $28.8 \mu \mathrm{L}$ of 4-tert-butylpyridine, and 17.5 $\mu \mathrm{L}$ of a stock solution of $520 \mathrm{mg} / \mathrm{mL}$ of lithium bis- (trifluoromethylsulfonyl) imide in acetonitrile.

Interdigitated electrodes:

A perovskite layer was deposited on $20 \times 20 \mathrm{~mm}^{2}$ glass as described below for photovoltaic devices. A shadow mask with an interdigitated pattern and $200 \mu \mathrm{m}$ channel length was used. Gold was thermally evaporated $(60 \mathrm{~nm})$ at a base pressure of $2 \times 10^{-6}$ 
mbar. Electrodes containing the monohydrate $\mathrm{MAPbI}_{3} \cdot\left(\mathrm{H}_{2} \mathrm{O}\right)$ described in the main text was prepared by introducing interdigitated electrodes containing $\mathrm{MAPbI}_{3}$ into a climate chamber (Dycomental, Model CCK) at $70{ }^{\circ} \mathrm{C}$ during $1 \mathrm{~h}$.

Photovoltaic Device fabrication: All the process was carried out outside the glovebox in ambient conditions at different humidity conditons. Photovoltaic devices were prepared over FTO glasses, which were partially etched with zinc powder and $\mathrm{HCl}$ (2 M). The substrates were cleaned with soap (Hellmanex) and rinsed with Milli-Q water and ethanol. Then, the substrates were sonicated for $15 \mathrm{~min}$ in a solution of acetone:isopropanol $(1: 1 \mathrm{v} / \mathrm{v})$, rinsed with ethanol and Milli-Q water, and dried with compressed air. After that, the substrates were treated in a $\mathrm{UV}-\mathrm{O}_{3}$ chamber for $15 \mathrm{~min}$. The $\mathrm{TiO}_{2}$ blocking layer was deposited onto the substrates by spray pyrolysis at $450{ }^{\circ} \mathrm{C}$, using a titanium diisopropoxide bis(acetylacetonate) solution diluted in ethanol (1:9, $\mathrm{v} / \mathrm{v}$ ), with oxygen as carrier gas. The spray was performed in 3 steps of $6 \mathrm{~s}$, spraying each time $5 \mathrm{~mL}$ (approx.), and waiting $30 \mathrm{~s}$ between steps. After the spraying process, the films were kept at $450{ }^{\circ} \mathrm{C}$ for $30 \mathrm{~min}$. The mesoporous $\mathrm{TiO}_{2}$ layer was deposited by spin coating at $2000 \mathrm{rpm}$ during $10 \mathrm{~s}$ using a $\mathrm{TiO}_{2}$ paste diluted in ethanol (1:5, weight ratio). After drying at $100{ }^{\circ} \mathrm{C}$ for $10 \mathrm{~min}$, the $\mathrm{TiO}_{2}$ mesoporous layer was heated at 500 ${ }^{\circ} \mathrm{C}$ for $30 \mathrm{~min}$ and later cooled to room temperature. Before the deposition of perovskite films, $100 \mu \mathrm{l}$ of a lithium bis-(trifluoromethylsulfonyl) imide $35 \mathrm{mM}$ solution in acetonitrile is prepared and deposited on the top of the device by spin-coating at 3000 rpm $(2000 \mathrm{ac})$ during 10 seconds. After that, the substrates are heated up at $450^{\circ} \mathrm{C}$ during $30 \mathrm{~min}$. The perovskite precursor solution $(50 \mu \mathrm{L})$ was spin-coated at $4000 \mathrm{rpm}$ for $50 \mathrm{~s}$. DMF is selectively washed with non-polar diethyl ether while one-step spincoating at $4000 \mathrm{rpm}$ is carried out. The diethyl ether needs to be added just before the white solid begins to crystallize in the substrate. At $30 \%$ R.H. the diethyl ether is added after 8-9 seconds of the substrate spinning and at $60 \%$ R.H. after 12-13 seconds. After deposition, the substrate was annealed at $100{ }^{\circ} \mathrm{C}$ for $3 \mathrm{~min}$. Then, the perovskite films were covered with the hole-transporting material (HTM) by dinamically spin coating at $4000 \mathrm{rpm}$ for $30 \mathrm{~s}$, using $50 \mu \mathrm{L}$ of spiro- OMeTAD solution. Finally, $60 \mathrm{~nm}$ of gold was thermally evaporated on top of the device to form the electrode contacts using a commercial Univex 250 chamber, from Oerlikon Leybold Vacuum.

\section{Film and Device characterization}

Ultraviolet-visible absorption spectra were recorded by a Cary 500 Scan VARIAN spectrophotometer in the $250-800 \mathrm{~nm}$ wavelength range. The morphology of the powders was observed using field-emission SEM using either a JEOL 7001F for powders. The XRD pattern of the prepared solids were measured using X-ray diffractometer (D8 Advance, Bruker-AXS) ( $\mathrm{Cu} \mathrm{K \alpha}$, wavelength $\lambda=1.5406 \AA$ ). Photovoltaic devices were characterized using an Abett Solar simulator equipped with 1.5 AM filter. The light intensity was adjusted to $100 \mathrm{mWcm}^{-2}$ using a calibrated $\mathrm{Si}$ solar cell. Devices were measured using a mask to define an active area of $0.11 \mathrm{~cm}^{2}$. 
Each data point shown in the graphs corresponds to an average of 20 independent devices.

\section{Results and discussion}

\section{Effect of additives on morphology and chemical defects}

During formation of the perovskite layer using the one step deposition method the correct stoichiometry of the $\mathrm{PbI}_{2}$ :MAI:additive intermediate complex needs to be generated as reported in the literature (Scheme 1). ${ }^{7}$ Very importantly, the solution coordination chemistry of the lead atom with solvent and additives will dictate the chemical species that will be generated in the films. ${ }^{25}$ In fact, several multiiodide plumbate ions chemical defects have been detected in films with proportions modulated by the processing conditions. For example, the effect of the solvent is key to stabilize the chemical defects and common solvents have been listed attending to the coordination ability towards $\mathrm{PbI}_{2}: \mathrm{H}_{2} \mathrm{O}>\mathrm{DMSO}>\mathrm{DMF}>\mathrm{GBL}$. As water molecules are the most coordinating molecules in the series it is clear that water present in the ambient will compete with DMSO and iodide ions present in the precursor solution during the spin coating process to generate $\mathrm{PbI}_{2}$ :MAI:Additive complex. Indeed, DMSO and $\mathrm{H}_{2} \mathrm{O}$ additives will strongly interact with solvent molecules and iodide ions in some cases displacing iodide ions coordinating the $\mathrm{Pb}$ as monitored by absorbance measurements in the supporting information. As it will be shown below the total amount of additives (i.e. DMSO and $\mathrm{H} 2 \mathrm{O}$ ) needs to be adjusted to provide the correct stoichiometry of the $\mathrm{PbI}_{2}$ :MAI:additive intermediate complex and a final $\mathrm{MAPbI}_{3}$ film free of chemical defects (Scheme 1). In the reported literature procedure the initial precursor solution contains a proportion 1:1:1 with a molar DMSO value of $n=1$ but the process is carried out in air. Interestingly, the total molar proportion of additive molecules coordinating $\mathrm{PbI}$ :MAI is higher in the ambient due to the presence of water $(\mathrm{m})$. A tentative optimum molar concentration of $n+m \approx 1.5$ will lead to adequate perovskite morphologies as discussed at the end of the manuscript. If the proportion of additives is not well balanced $(n+m \neq 1.5)$ films will show inadequate morphology and the presence of chemical defects. Here, we note that the actual humidity of the ambient modifies the crystallization kinetics of the intermediate complex. In particular, at $60 \%$ R.H. the intermediate complex crystallizes about 5 seconds later than at $30 \%$ R.H. under our deposition conditions and the diethyl ether addition needs to be modified accordingly.

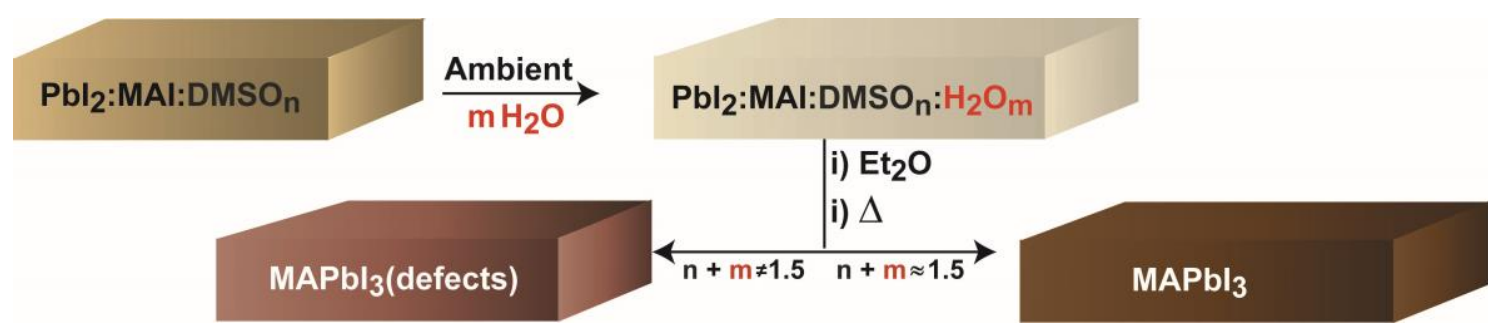

Scheme 1: Schematic representation of key steps during the one-step fabrication process that takes into account the effect of ambient water. 
In order to provide understanding on the impact of additives (i.e. DMSO or $\mathrm{H}_{2} \mathrm{O}$ ) on the morphology during perovskite generation several films were prepared under different conditions and were characterized by SEM analysis and absorbance measurements. Figure 1 shows SEM images of representative films/devices fabricated using different DMSO:Pb ratios at constant R.H. (40\%). Therefore, the proportion of $\mathrm{H}_{2} \mathrm{O}$ ( $\mathrm{m}$ in Scheme 1) introduced in the system will be fixed. In the following discussion we refer to the DMSO:Pb ratio as a tool to modify the proportion $\mathrm{n}$ of DMSO in the complex as this will be the key parameter to control the crystallization as a function of the humidity conditions. The top view image (Figure 1a) of a device fabricated with a low proportion of DMSO (Ratio 0.5 ) clearly shows a fiber-like morphology typical from materials fabricated from pure DMF. ${ }^{21,25,26}$ This result not only indicates that the proportion of DMSO is insufficient to generate the $\mathrm{PbI}_{2}: \mathrm{MAI}$ :Additive complex but also reveals the presence of uncovered electrode surface which will lead to the hole transport layer (HTL) to be in direct contact with the electron transport layer (ETL). As the DMSO proportion is increased to a DMSO: $\mathrm{Pb}$ ratio of 1.0 the complex is formed correctly as reported by Ahn et al. ${ }^{7}$ We observe a final morphology characterized by the presence of compact films with perovskite domains in the order of 100-500 nm (Figure 1b). Therefore, the correct formation of the intermediate complex followed by the thermal treatment promotes the slow evaporation of the weakly bound DMSO providing the adequate morphology with a totally covered surface. Finally, a further increase of DMSO to a ratio of 1.5 (Figure 1c) also leads to large crystalline domains similar to those in Figure 1b. Interestingly, a large proportion of pinholes develops with cylindrical shape typical from gas evaporation from a quasi-solid state. Indeed, it is expected that the additional $0.5 \mathrm{~mol}$ of DMSO exceeding the adequate complex ratio will evaporate under the thermal treatment and the extra occupied volume will lead to voids in the film. It is also noted the presence of domains with large differences in contrast. Light grey domains corresponds to domains containing large proportion of heavy atoms (i.e. $\mathrm{Pb}$ or I) and dark domains contain larger proportion of lighter atoms such as carbon or oxygen like those expected from remaining DMSO in the films. We note that this type of morphology has recently been observed by Yang et al. ${ }^{27}$ using GBL/DMSO mixtures. In that case it was shown that an additional treatment with $\mathrm{MABr}$ was able to recover a morphology like that shown in Figure 1b. These results point to the possibility that multiiodide plumbates with a number of iodide ions $<6$ are being stabilized by DMSO and the MABr treatment is able to recover the $\mathrm{PbX}_{6}{ }^{4-}$ octahedra. The presence of bound DMSO will be confirmed below by absorption measurements. Analysis of the crosssection images (Figure 1d, 1e and 1f) is quite revealing as the presence of pinholes in the perovskite layer is observed for devices fabricated with $\mathrm{PbI}_{2}$ :DMSO ratio of 0.5 and 1.5. These pinholes will inevitably lead to the direct contact between the SpiroOMeTAD with the mesoporous layer of $\mathrm{TiO}_{2}$ providing additional carrier recombination pathways, as it will be discussed in the final part of the manuscript. 


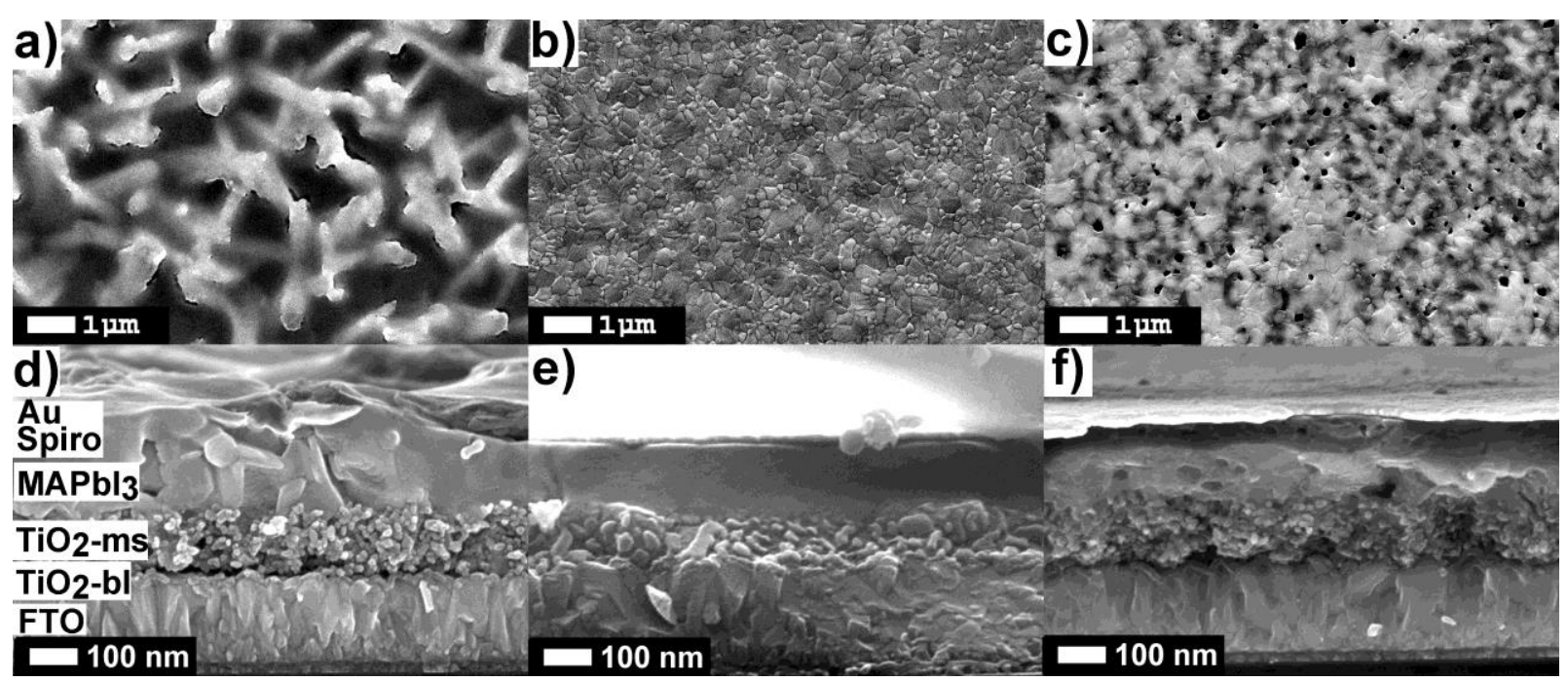

Figure 1: SEM images of devices fabricated at $40 \%$ R.H. using different DMSO:Pb ratios: 0.5 ( $\mathrm{a}$ and $\mathrm{d}), 1.0$ ( $\mathrm{b}$ and e) and 1.5 ( $\mathrm{d}$ and $\mathrm{f}$ ). Top view (a, b and c) and crosssection (d, e and $\mathrm{f})$.

Alternatively, absorption measurements have proved recently useful to detect chemical defects in perovskite films. Theoretical absorption bands of pure $\mathrm{MAPbI}_{3}$ are characterized by the presence of two bands at $\lambda_{\max } \approx 500 \mathrm{~nm}$ and $\lambda_{\max } \approx 760 \mathrm{~nm}$ as reported by de Angelis et al. using DFT calculations. ${ }^{28}$ Alternatively, experimental absorption bands of $\mathrm{MAPbI}_{3}$ films are usually more complex showing the presence of additional bands below $500 \mathrm{~nm}$. Indeed, several species have been observed in films by different authors such as $\mathrm{PbIS}_{5}^{+}, \mathrm{PbI}_{2} \mathrm{~S}_{4}, \mathrm{PbI}_{3} \mathrm{~S}_{3}{ }^{-}, \mathrm{PbI}_{4} \mathrm{~S}_{2}{ }^{2-}, \mathrm{PbI}_{5} \mathrm{~S}^{3-}, \mathrm{PbI}_{6}^{4-}$ and $\left(\mathrm{Pb}_{2} \mathrm{I}_{4}\right)_{\mathrm{n}}$ chains all responsible for the bands in the region of $\approx 500 \mathrm{~nm} \cdot{ }^{21,29,25}$ Furthermore and to provide a complete picture of the absorbance response we also need to note that substrates partially covered by $\mathrm{MAPbI}_{3}$ films are characterized by strong scattering $>750 \mathrm{~nm}$. This scattering observed when measurements are carried out using regular spectrophotometers, as opposed to optical microscopy of single crystals, leads to artifacts decreasing the intensity of bands in the range of $250-750 \mathrm{~nm} .{ }^{30}$ 

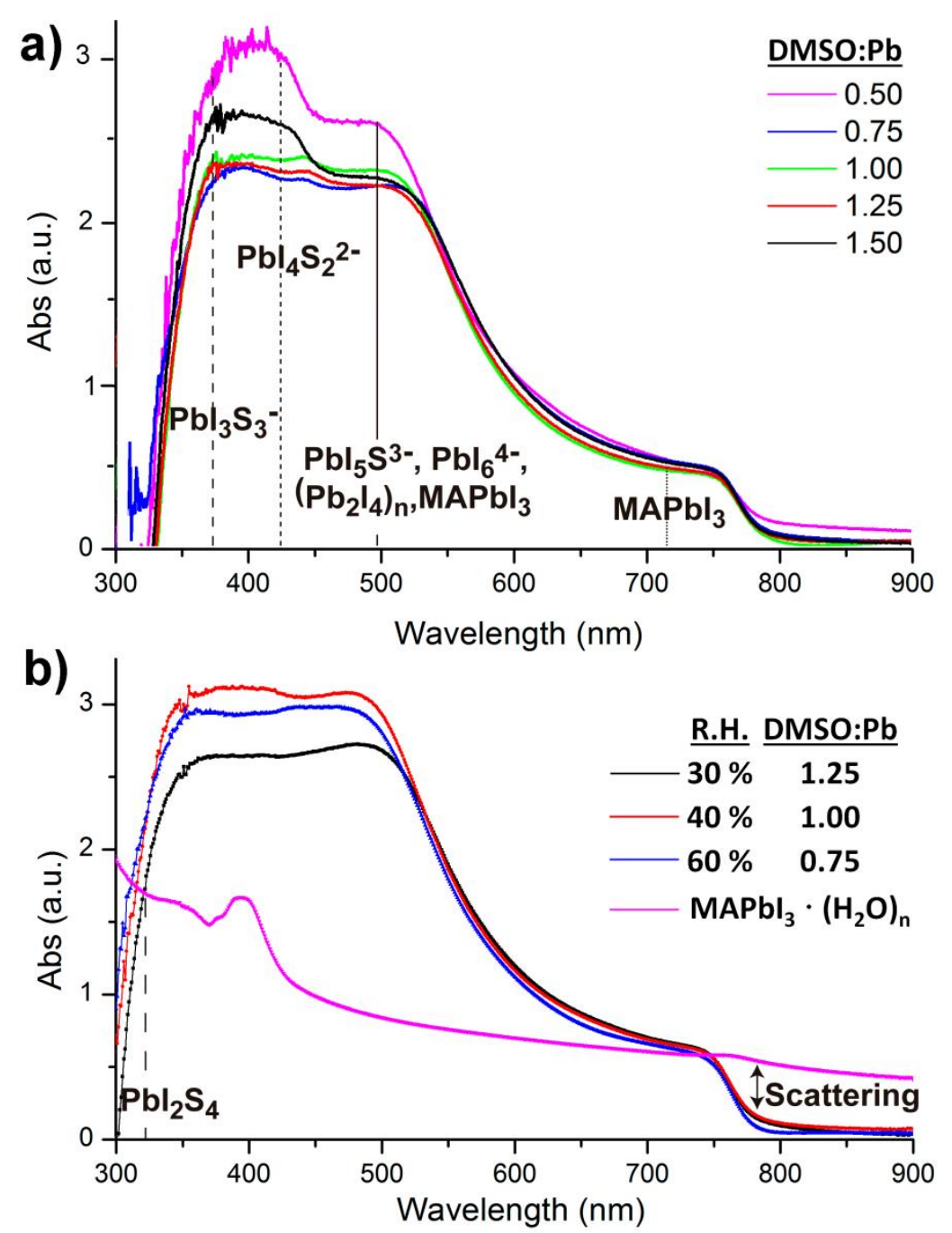

Figure 2: a) Absorption spectra of $\mathrm{MAPbI}_{3}$ films measured as a function of the DMSO:Pb ratio used in the precursor solution, films fabricated at $\mathrm{R} . \mathrm{H} .=40 \%$. b) Absorption measurements of MAPbI3 films prepared under optimum DMSO:Pb ratio at different humidity conditions. $\lambda_{\max }$ for representative multiiodide plumbate ions are represented as vertical lines where $\mathrm{S}=$ solvent.

In this work, the absorption of $\mathrm{MAPbI}_{3}$ films is studied as a function of the DMSO: $\mathrm{Pb}$ ratio used in the precursor solution fabricated at R.H. $=40 \%$, similar conditions to those used for the SEM analysis. Figure 2a shows similar absorption band intensities in the $750 \mathrm{~nm}$ region for all films pointing to equal thickness of $\mathrm{MAPbI}_{3}$ layer. Alternatively, absorption bands intensity in the region 350-550 nm strongly depends on the DMSO:Pb ratio. Films containing a ratio of 0.75 to 1.25 are very flat in the high energy region and are characterized by a morphology containing large crystalline domains as those shown in Figure $1 \mathrm{~b}$ with no pinholes. Alternatively, films with a fiber-like morphology (0.5 ratio, Figure 1a) or presence of holes (1.5 ratio, Figure 1c) show bands at $350-550 \mathrm{~nm}$ with increased intensity, just where several multiodide plumbate species show their maximum absorbance. In particular, it appears that films 
containing high surface of grain boundaries do show increased intensities for multiplumbate ions such as $\mathrm{PbI}_{3} \mathrm{~S}_{3}{ }^{-}, \mathrm{PbI}_{4} \mathrm{~S}_{2}{ }^{2-}, \mathrm{PbI}_{5} \mathrm{~S}^{3-}, \mathrm{PbI}_{6}{ }^{4-}$ or $\left(\mathrm{Pb}_{2} \mathrm{I}_{4}\right)_{\mathrm{n}}$. During film formation the highly coordinating DMSO is able to stabilize the species as noted in the SEM image Figure 1c where the dark domains mostly appear around the holes indicating that DMSO remains in the film rather localized in this area. We note that a morphology presenting holes (Figure 1c) lead to short PL decay time indicating that species associated to the grain boundaries play a very important role in the recombination pathways. ${ }^{27}$ Analysis of the precise proportion and the electrical effect of each of these species is beyond the scope of this work but in any case it appears difficult to separate physical and morphology effects.

\section{Relative humidity effect on chemical defects and electrical properties}

There are some precedents in the literature of film formation under different humidity atmospheres paying special attention to the effect on the morphology. For example, Snaith et al. described generation of non-continuous morphologies under high R.H. with significantly improved photoluminescence and fast film formation. ${ }^{6}$ However, a correlation between generated species on films at humid environments and electrical properties has not been described. Here, we proceed to study the effect of water by modifying the relative humidity during processing of the devices. According to the process described in Scheme 1 and the competing displacement reactions described previously it is clear that water present in environmental humidity can be regarded as an additive which will affect crystallization of the perovskite layer. For this purpose the DMSO: $\mathrm{Pb}$ ratio has been modified for films fabricated at different humidity conditions and complete absorption data is shown as supporting information. Absorption results at $30 \%$ and $60 \%$ R.H. show similar trends as those observed in Figure 2a with bands with increased intensity in the $350-550 \mathrm{~nm}$ region when the amount of water and DMSO is not properly balanced to obtain the intermediate complex. Alternatively, it is very interesting to note that flat absorbance profiles in the region $350-550 \mathrm{~nm}$ is only obtained when the DMSO/ $\mathrm{H}_{2} \mathrm{O}$ concentration is controlled at given humidity conditions (Figure $2 \mathrm{~b}$ ). This certainly agrees with a competitive process to coordinate the $\mathrm{Pb}$ core between DMSO and $\mathrm{H}_{2} \mathrm{O}$. For example, as the humidity increases to R.H. $=60 \%$ a lower amount of DMSO is required to provide large crystalline domains as $\mathrm{H}_{2} \mathrm{O}$ is acting as an additive to form the $\mathrm{PbI}_{2}$ :MAI:additive intermediate complex. Alternatively, when R.H. is reduced to $30 \%$ increased amount of DMSO:Pb of $1.0-1.25$ is required to obtain optimum morphology with reduced amount of multiiodide plumbate defects.

The electrical properties of hydrate complexes can be monitored by preparation of interdigitated electrodes containing perovskite hydrates. Here we follow a reported process to produce $\mathrm{MAPbI}_{3}$ hydrates from $\mathrm{MAPbI}_{3}$ films using a climatic chamber at R.H. $=80 \%$ and $60{ }^{\circ} \mathrm{C}$ during 60 min. ${ }^{17}$ Leguy et al. have optically characterized $\mathrm{MAPbI}_{3} \cdot \mathrm{H}_{2} \mathrm{O}$ using ellipsometry measurements and showed the material to form nearly colorless needles. Needles of similar morphology as previously described are obtained 
as observed by SEM (Figure 3a). The hydrate species generate wires of variable size but some exceeding lengths of $100 \mu \mathrm{m}$. A close inspection into the morphology shows that the wires are not totally compact. In addition, a picture of the film is shown as supporting information where the white colour of the perovskite hydrate can be observed. The XRD spectra shown as supporting information show some peaks which may be related to the $\mathrm{MAPbI}_{3} \cdot \mathrm{H}_{2} \mathrm{O}$ complex $\left(2 \theta=25.4^{\circ}, 28.4^{\circ}\right.$ and $\left.31.9^{\circ}\right)$ as compared with the theoretical powder spectra. In addition, some crystalline $\mathrm{MAPbI}_{3}$ domains indicating that the weakly bound water molecules have been released during the XRD measurement. Finally, degradation product $\mathrm{PbI}_{2}$ is also detected. However, other amorphous hydrate complexes may be present as well. Absorption spectra of the film is shown in Figure $2 b$ and high degree of scattering is observed above $750 \mathrm{~nm}$ which will reduce the intensity of bands below this wavelength value as described before. In any case a band is observed at $400 \mathrm{~nm}$ typical from $\mathrm{PbI}_{3} \mathrm{~S}_{3}{ }^{-}$or $\mathrm{PbI}_{4} \mathrm{~S}_{2}{ }^{2}$ species and higher intensity bands appear below $350 \mathrm{~nm}$ that extends beyond $300 \mathrm{~nm}$ corresponding to species with still lower amount of iodides.

The electrical properties of the hydrate were probed in an interdigitated electrode configuration $\left(\mathrm{Au} / \mathrm{MAPbI}_{3} \cdot\left(\mathrm{H}_{2} \mathrm{O}\right) \mathrm{n} / \mathrm{Au}\right)$ with a $200 \mu \mathrm{m}$ channel length on glass, see inset Figure $3 \mathrm{~b}$. Using similar a configuration conductivity of $\mathrm{MAPbI}_{3}$ has been measured by Johansson et al. ${ }^{31}$ and Müller et al. noted that conductivity increases with exposure to humid ambient conditions but pure films containing $\mathrm{MAPbI}_{3} \cdot\left(\mathrm{H}_{2} \mathrm{O}\right) \mathrm{n}$ hydrates have not been reported to this date. ${ }^{18}$ Current-Voltage measurements were carried out in ambient conditions in the dark at scan rates of $100 \mathrm{mV} / \mathrm{s} . I-V$ curves of $\mathrm{MAPbI}_{3}$ and $\mathrm{MAPbI}_{3} \cdot\left(\mathrm{H}_{2} \mathrm{O}\right) \mathrm{n}$ show Ohmic behavior with higher currents for the monohydrate complex of nearly six order of magnitudes at $\pm 1 \mathrm{~V}$. We note that stability of the interdigitated electrode containing $\mathrm{MAPbI}_{3} \cdot\left(\mathrm{H}_{2} \mathrm{O}\right) \mathrm{n}$ is low due to the large currents passing through the wires with a small diameter. Taking into account the device configuration conductivity values of the perovskite in the order of $1 \times 10^{-8} \mathrm{Scm}^{-1}$ and $8 \times 10^{-1} \mathrm{Scm}^{-1}$ are calculated, respectively. These results are in good agreement with previously reported results in interdigitated configuration and highlight that extremely sensitivity of the perovskites to moisture environment. We also note that conductivity values have been calculated attending to the geometric area defined by the gold contacts/perovskite layer. However, the real active area relevant for the calculation will be much smaller as it is defined by the hydrate wires in direct contact with the gold electrode. Therefore, the provided conductivity value of $\mathrm{MAPbI}_{3} \cdot \mathrm{H}_{2} \mathrm{O}$ only provides the low conductivity limit. In conclusion, the presence of hydrates will increase the conductivity of the perovskite layer several orders of magnitude and this will create alternative pathways for carriers to reach the contacts that may lead to shunting or a reduction of the selectivity of the contacts. 


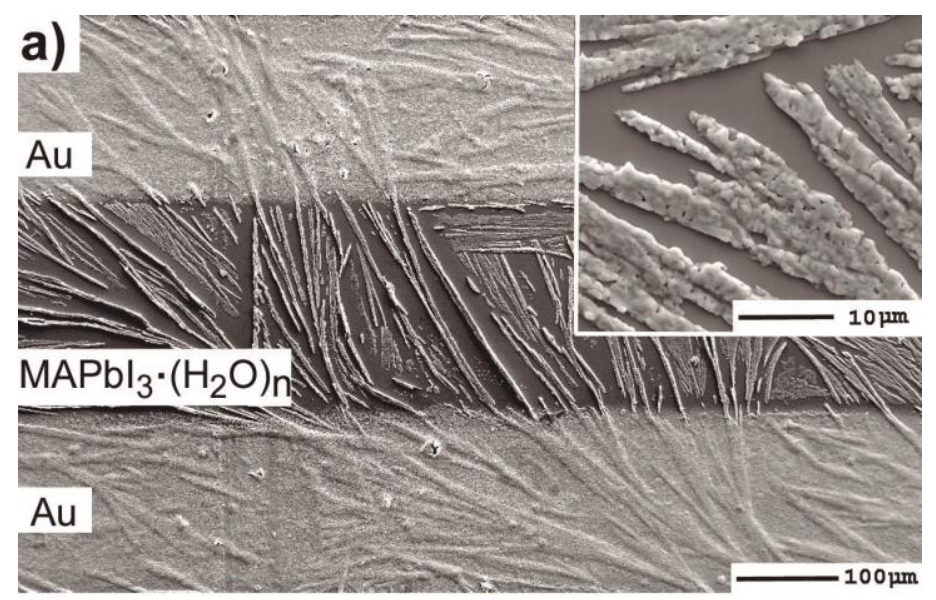

\section{b)}

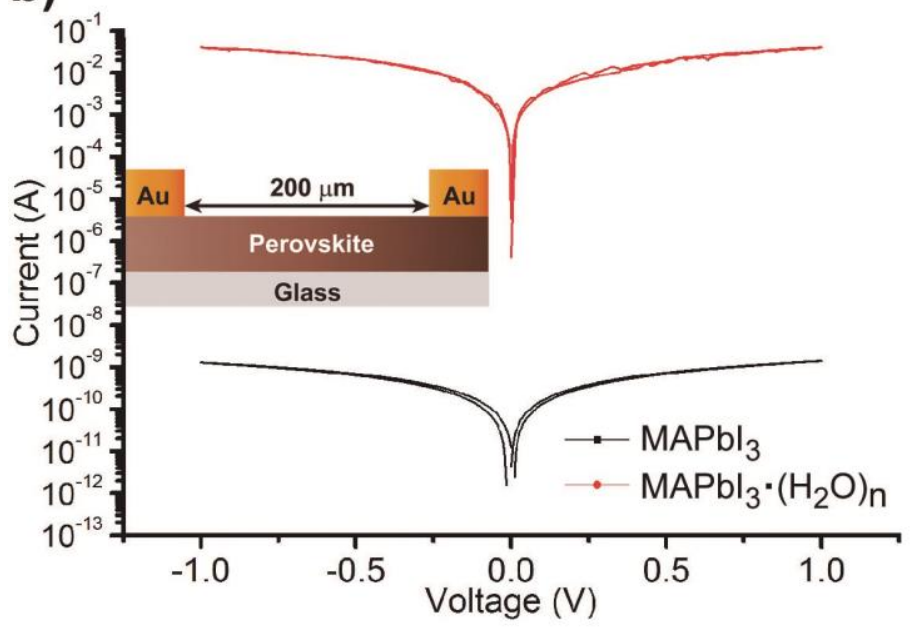

Figure 3: a) SEM image of an interdigitated electrode in the configuration $\mathrm{Au} /$ $\mathrm{MAPbI}_{3} \cdot\left(\mathrm{H}_{2} \mathrm{O}\right)_{\mathrm{n}} / \mathrm{Au}$ with a $200 \mu \mathrm{m}$ channel. b) Current-Voltage curve of interdigitated electrode in the configuration shown in a) for devices containing either $\mathrm{MAPbI}_{3}$ or $\mathrm{MAPbI}_{3} \cdot\left(\mathrm{H}_{2} \mathrm{O}\right)_{\mathrm{n}}$.

\section{Impact of Water and Additives on photovoltaic devices}

Now that the coordination chemistry of DMSO and $\mathrm{H}_{2} \mathrm{O}$ has been correlated with film formation morphology, absorbance and electrical properties we proceed to analyze the effect of DMSO and $\mathrm{H}_{2} \mathrm{O}$ in photovoltaic devices. Devices are fabricated in the configuration $\mathrm{FTO} / \mathrm{TiO}_{2}-\mathrm{bl} / \mathrm{TiO}_{2}$-meso/MAPbI $3 /$ Spiro-OMeTAD/Au where the DMSO: $\mathrm{Pb}$ ratio is varied under different series in humidity conditions. In order to be able to compare with the previous sections of the manuscript the same processing conditions have been used and results the same. Each data point shown in Figure 4 corresponds to an average of 20 independent devices measured under reverse bias conditions at a scan rate of $50 \mathrm{mV} / \mathrm{s}$. Overall, device efficiency can be increased from $10.8 \%$ to $18.6 \%$ by carefully adjusting the DMSO:Pb ratio attending to the R.H.

At a given humidity conditions we observe that photocurrent $(J S c)$ of devices varies from $\approx 20-22 \mathrm{~mA} / \mathrm{cm}^{2}$ with the DMSO:Pb being higher for ratios between 0.75 and 1.25 . Increased photocurrents are the result of an adequate morphology containing large 
crystalline domains with little presence of chemical impurities in the films. Lower photocurrents are obtained with devices at either low or high DMSO:Pb ratio as a result of inadequate morphology (Figure 1a and 1c) and presence of multiiodide plumbate species (Figure 2a). Note that absolute absorbance values are higher for films fabricated with low and high DMSO:Pb ratios (Figure 2a) but photocurrents are lower indicating that the presence of the chemical species are related with recombination pathways. Alternatively, at the highest humidity conditions the achievable photocurrent decreases indicating that the perovskite hydrate leads to increased recombination pathways. The open-circuit potential $\left(\mathrm{V}_{\mathrm{oc}}\right)$ of the devices is rather insensitive to the DMSO:Pb ratio and seems to be more connected to the humidity conditions. Indeed, devices fabricated at R.H. $=60 \%$ show $\mathrm{V}_{\mathrm{oc}}$ about $100 \mathrm{mV}$ lower than those fabricated at low humidity conditions. It has been shown the highly conductive nature of the $\mathrm{MAPbI}_{3} \cdot\left(\mathrm{H}_{2} \mathrm{O}\right) \mathrm{n}$ hydrates. Then, it is clear that the monohydrate can act as charge carriers percolation pathways leading to shunting of the devices. This effect is more severe at low DMSO conditions (ratio of 0.5 ) where synthesis of the hydrate complex is maximized by reduction of competing molecules. Indeed, shunting pathways are already observed in the SEM cross-section of Figure 1d. Fill Factor (FF) of devices shows a similar trend to that of $J s c$ ranging from 60 to 78 representing depending on the processing conditions, this difference represents a $25 \%$ increase for adequate conditions. In this regard increased DMSO and $\mathrm{H}_{2} \mathrm{O}$ proportions during the processing conditions of the device lead to the lowest values. Therefore, it appears that not only the film morphology needs to be adequate but there should not be any excess of highly coordinating molecules as they seem to increase all recombination processes.

Very interestingly, at each humidity conditions the maximum efficiency can be maximized by tuning the DMSO:Pb ratio to obtain the correct intermediate complex stoichiometry. For example, at R.H. of $30 \%$ the observed optimum DMSO:Pb ratio is 1.25 providing highest efficiencies in the series of $18.7 \%\left(V_{\mathrm{oc}}=1.05 \mathrm{~V}, J_{\mathrm{sc}}=22.4\right.$ $\mathrm{mA} / \mathrm{cm}^{2}$ and $F F=78$ ). At a given humidity conditions the required $\mathrm{DMSO}: \mathrm{Pb}$ ratio to provide maximum efficiencies decreases as the R.H. increases. Indeed, at R.H. $=60 \%$ ratios of $0.75-1.00$ offer maximum efficiencies of $\approx 14.5 \%\left(V_{\mathrm{oc}}=1.00 \mathrm{~V}, J_{\mathrm{sc}}=20.5\right.$ $\mathrm{mA} / \mathrm{cm}^{2}$ and $F F=72$ ). This result clearly indicates that competition between DMSO and $\mathrm{H}_{2} \mathrm{O}$ molecules is readily taking place following coordination chemistry reactions as those discussed previously. Interestingly, absorbance spectra of films providing the highest efficiency at each humidity conditions (Figure 2b) are flat in the range 350-550 $\mathrm{nm}$ indicating the presence of multiiodide plumbate ions are minimized. It is important to highlight that error bars are larger when low proportion of DMSO is used due to the presence of pinholes. The reduction in Jsc and $\mathrm{V}_{\mathrm{oc}}$ in the presence of vapour water molecules is in agreement with the work by Leguy et al. as they observed up to a $90 \%$ drop in short-circuit photocurrent and $200 \mathrm{mV}$ loss in open-circuit potential Voc during degradation experiments. ${ }^{17}$ In addition, extrapolation of the linear tendency observed in Figure $4 \mathrm{~b}$ can also be used to calculate the ideal proportion of additives in a 
situation when no water is present (i.e. in a glovebox) providing the values $n+m \approx 1.5$ used in different parts of the manuscript.
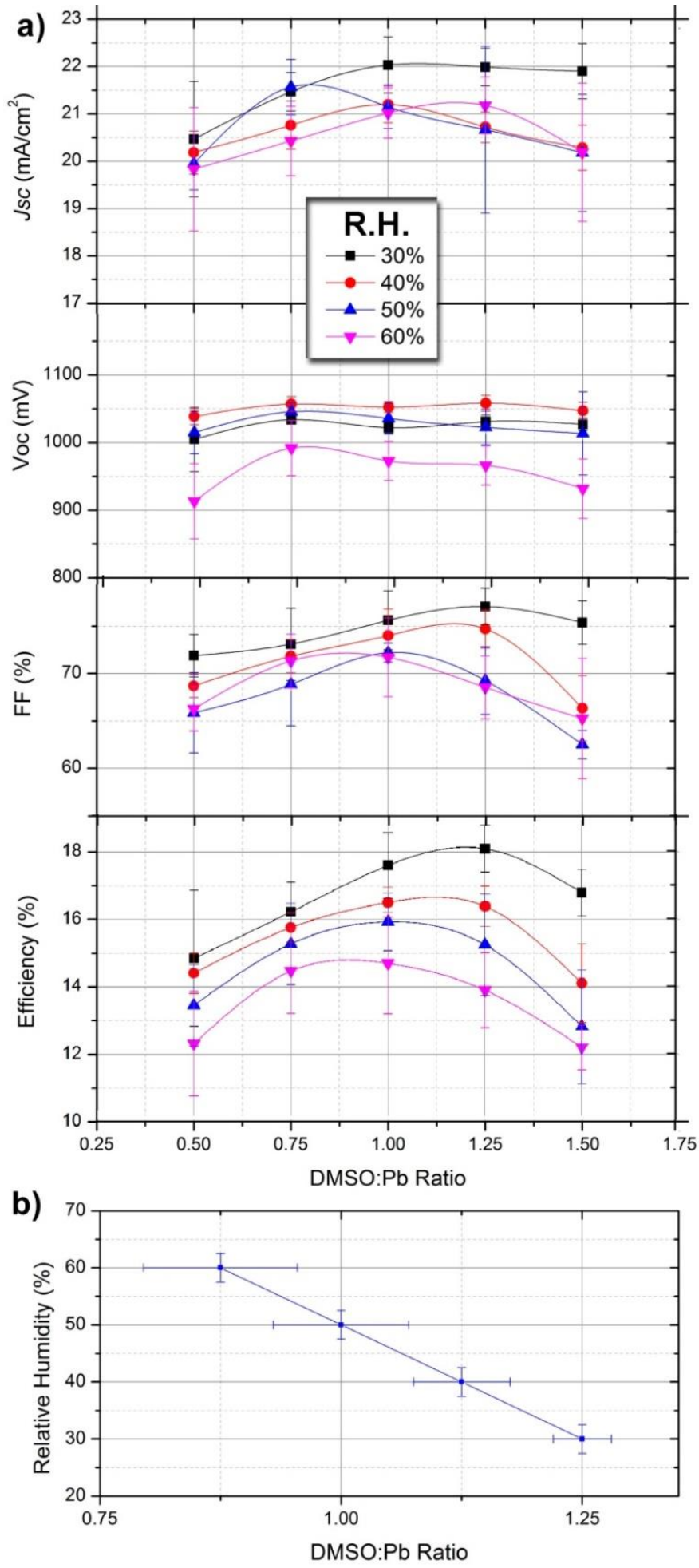

Figure 4: a) Efficiency parameters of devices fabricated in the configuration $\mathrm{FTO} / \mathrm{TiO}_{2}-\mathrm{bl} / \mathrm{TiO}_{2}-\mathrm{meso} / \mathrm{MAPbI}_{3} / \mathrm{Spiro}-\mathrm{OMeTAD} /$ as a function to the $\mathrm{DMSO}: \mathrm{Pb}$ ratio used in the precursor solution fabricated under different relative humidity conditions. $b$ ) Observed maximum efficiency as a function of relative humidity and DMSO:Pb ratio. 
From this data we note that the presence of water is in general negative for the final devices performance but its effect can be minimized by correctly formulating the precursor solution. Indeed, higher efficiencies are obtained for devices prepared under low humidity conditions but in all cases DMSO:Pb ratio needs to be adjusted to provide maximum efficiencies. Very importantly, Figure $4 \mathrm{~b}$ offers reference data for the reader to implement in their own processes taken into account different humidity conditions. In addition, we noted that stability of devices prepared at $60 \%$ R.H. were somehow lower than those prepared under $30 \%$ R.H. during characterization under light and voltage conditions. However, further complete studies are required to confirm these preliminary results.

\section{Conclusions}

In the field of lead halide perovskite solar cells highest reported efficiencies are typically obtained for layers processed under a totally dry environment that ultimately increases the production costs. This manuscript presents new insights to minimize the negative effect of environmental water enabling the processing of solar cells in ambient air with high efficiencies and reproducibility. It is shown that the $\mathrm{H}_{2} \mathrm{O} / \mathrm{DMSO}$ ratio needs to be carefully adjusted to obtain adequate morphology and to reduce the presence of chemical defects. Both molecules compete to coordinate to the $\mathrm{Pb}$ atom which will limit the formation of the intermediate complex $\mathrm{PbI}_{2}$ :MAI:Additive responsible for the final properties of the films. High efficiency devices processed in air with PCE approaching $19 \%$ can be obtained for the simplest perovskite formulation $\mathrm{MAPbI}_{3}$ under different humidity conditions.

Supporting Information. Methods, further absorption measurements, XRD data.

\section{Acknowledgements}

We thank financial support by MINECO of Spain under project (MAT2013-47192C3-1-R), and Generalitad Valenciana is acknowledged for financial support on the DISOLAR2 Project (PROMETEOII/2014/020). A. G. would like to thank the Spanish Ministerio de Economía y Competitividad for a Ramón y Cajal Fellowship (RYC-201416809). Serveis Centrals at UJI (SCIC) are acknowledged for the SEM measurement assistance. 


\section{References}

1. M. A. Green, K. Emery, Y. Hishikawa, W. Warta and E. D. Dunlop, Prog. Photovoltaics: Research and Applications, 2015, 23, 1-9.

2. M. Saliba, T. Matsui, K. Domanski, J.-Y. Seo, A. Ummadisingu, S. M. Zakeeruddin, J.-P. Correa-Baena, W. R. Tress, A. Abate, A. Hagfeldt and M. Grätzel, Science, 2016, DOI: 10.1126/science.aah5557.

3. J. P. Correa Baena, L. Steier, W. Tress, M. Saliba, S. Neutzner, T. Matsui, F. Giordano, T. J. Jacobsson, A. R. Srimath Kandada, S. M. Zakeeruddin, A. Petrozza, A. Abate, M. K. Nazeeruddin, M. Gratzel and A. Hagfeldt, Energy Environ. Sci., 2015, 8, 2928-2934.

4. H. Zhou, Q. Chen, G. Li, S. Luo, T.-b. Song, H.-S. Duan, Z. Hong, J. You, Y. Liu and Y. Yang, Science, 2014, 345, 542-546.

5. J. You, Y. Yang, Z. Hong, T.-B. Song, L. Meng, Y. Liu, C. Jiang, H. Zhou, W.H. Chang and G. Li, Appl. Phys. Lett., 2014, 105, 183902

6. G. E. Eperon, S. N. Habisreutinger, T. Leijtens, B. J. Bruijnaers, J. J. van Franeker, D. W. deQuilettes, S. Pathak, R. J. Sutton, G. Grancini, D. S. Ginger, R. A. J. Janssen, A. Petrozza and H. J. Snaith, ACS Nano, 2015, 9, 9380-9393.

7. N. Ahn, D.-Y. Son, I.-H. Jang, S. M. Kang, M. Choi and N.-G. Park, J. Am. Chem. Soc., 2015, 137, 8696-8699.

8. M. I. Saidaminov, A. L. Abdelhady, B. Murali, E. Alarousu, V. M. Burlakov, W. Peng, I. Dursun, L. Wang, Y. He, G. Maculan, A. Goriely, T. Wu, O. F. Mohammed and O. M. Bakr, Nat. Commun., 2015, 6.

9. Y.-J. Jeon, S. Lee, R. Kang, J.-E. Kim, J.-S. Yeo, S.-H. Lee, S.-S. Kim, J.-M. Yun and D.-Y. Kim, Sci. Rep., 2014, 4, 6953.

10. P.-W. Liang, C.-Y. Liao, C.-C. Chueh, F. Zuo, S. T. Williams, X.-K. Xin, J. Lin and A. K. Y. Jen, Adv. Mater., 2014, 26, 3748-3754.

11. Y. Wu, A. Islam, X. Yang, C. Qin, J. Liu, K. Zhang, W. Peng and L. Han, Energy Environ. Sci., 2014, 7, 2934-2938.

12. D. Shi, V. Adinolfi, R. Comin, M. Yuan, E. Alarousu, A. Buin, Y. Chen, S. Hoogland, A. Rothenberger and K. Katsiev, Science, 2015, 347, 519-522.

13. P. K. Nayak, J. Bisquert and D. Cahen, Adv. Mater., 2011, 23, 2870-2876.

14. W. S. Yang, J. H. Noh, N. J. Jeon, Y. C. Kim, S. Ryu, J. Seo and S. I. Seok, Science, 2015, 348, 1234-1237.

15. C.-G. Wu, C.-H. Chiang, Z.-L. Tseng, M. K. Nazeeruddin, A. Hagfeldt and M. Gratzel, Energy Environ. Sci., 2015, 8, 2725-2733.

16. L. Li, Y. Chen, Z. Liu, Q. Chen, X. Wang and H. Zhou, Adv. Mater., 2016, DOI: 10.1002/adma.201603021. 
17. A. M. A. Leguy, Y. Hu, M. Campoy-Quiles, M. I. Alonso, O. J. Weber, P. Azarhoosh, M. van Schilfgaarde, M. T. Weller, T. Bein, J. Nelson, P. Docampo and P. R. F. Barnes, Chem. Mater., 2015, 27, 3397-3407.

18. C. Müller, T. Glaser, M. Plogmeyer, M. Sendner, S. Döring, A. A. Bakulin, C. Brzuska, R. Scheer, M. S. Pshenichnikov, W. Kowalsky, A. Pucci and R. Lovrinčić, Chem. Mater., 2015, 27, 7835-7841.

19. W. Zhou, Y. Zhao, C. Shi, H. Huang, J. Wei, R. Fu, K. Liu, D. Yu and Q. Zhao, J. Phys Chem. C, 2016, 120, 4759-4765.

20. J. M. Frost, K. T. Butler, F. Brivio, C. H. Hendon, M. van Schilfgaarde and A. Walsh, Nano Lett., 2014, 14, 2584-2590.

21. Y. Guo, K. Shoyama, W. Sato, Y. Matsuo, K. Inoue, K. Harano, C. Liu, H. Tanaka and E. Nakamura, J. Am. Chem. Soc., 2015, 137, 15907-15914.

22. J. You, L. Meng, T.-B. Song, T.-F. Guo, Y. M. Yang, W.-H. Chang, Z. Hong, H. Chen, H. Zhou, Q. Chen, Y. Liu, N. De Marco and Y. Yang, Nat. Nanotech., 2016, 11, $75-81$.

23. J. H. Heo, D. H. Song and S. H. Im, Adv. Mater., 2014, 26, 8179-8183.

24. K. Domanski, J.-P. Correa-Baena, N. Mine, M. K. Nazeeruddin, A. Abate, M. Saliba, W. Tress, A. Hagfeldt and M. Grätzel, ACS Nano, 2016, 10, 6306-6314.

25. S. Rahimnejad, A. Kovalenko, S. Martí-Forés, C. Aranda and A. Guerrero, ChemPhysChem, 2016, 17, 2795.

26. E. Horváth, M. Spina, Z. Szekrényes, K. Kamarás, R. Gaal, D. Gachet and L. Forró, Nano Lett., 2014, 14, 6761-6766.

27. M. Yang, T. Zhang, P. Schulz, Z. Li, G. Li, D. H. Kim, N. Guo, J. J. Berry, K. Zhu and Y. Zhao, Nat. Commun., 2016, 7.

28. P. Umari, E. Mosconi and F. De Angelis, Sci. Rep., 2014, 4, 4467.

29. K. Yan, M. Long, T. Zhang, Z. Wei, H. Chen, S. Yang and J. Xu, J. Am. Chem. Soc., 2015, 137, 4460-4468.

30. Y. Tian and I. G. Scheblykin, J. Phys Chem. Lett., 2015, 6, 3466-3470.

31. K. Sveinbjörnsson, K. Aitola, X. Zhang, M. Pazoki, A. Hagfeldt, G. Boschloo and E. M. J. Johansson, J. Phys Chem. Lett., 2015, 6, 4259-4264. 


\section{Table of Contents (TOC)}

Environmental water affects the crystallization dynamics and presence of defects in the perovskite films

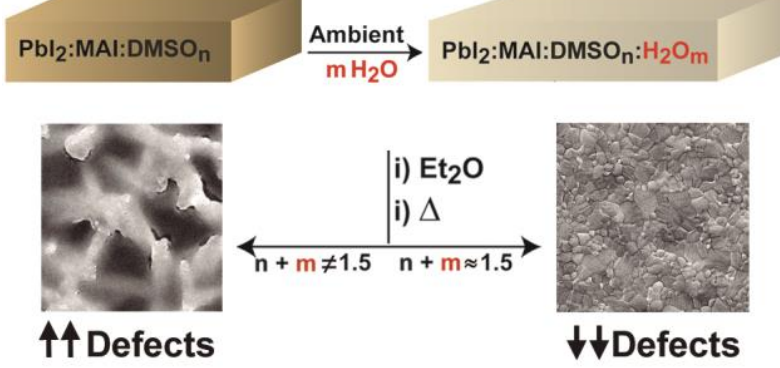

